\title{
Research Square \\ Improvement of stability for cellulose polymer by calcium oxide for application to porous materials
}

Hye Ji Lee

Sangmyung University - Seoul Campus: Sangmyung University

SANG WOOK KANG ( $\nabla$ swkang@smu.ac.kr)

Sangmyung University https://orcid.org/0000-0001-7211-4064

\section{Research Article}

Keywords:

Posted Date: March 1st, 2021

DOI: https://doi.org/10.21203/rs.3.rs-184385/v1

License: (c) (i) This work is licensed under a Creative Commons Attribution 4.0 International License. Read Full License 


\section{Abstract}

In this study, calcium oxide ( $\mathrm{CaO}$ ) was used as an additive to form pores in a cellulose acetate (CA) membrane and at the same time improve the thermal stability of the cellulose acetate membrane. When the $\mathrm{CA} / \mathrm{CaO}$ membrane was exposed to water pressure, the solvent was removed from the CA matrix area plasticized by the $\mathrm{CaO}$ particle size and water channels were formed. In addition, the high melting point of $\mathrm{CaO}$ and its bonding with the carbonyl group of $\mathrm{CA}$ caused a crosslinking effect.

We succeeded in membrane synthesis with a high porosity of $73.1 \%$ and flux data of $95.25 \mathrm{~L} / \mathrm{m}^{2} \mathrm{~h}$ at 8 bar, which was enhanced thermally with an increased decomposition temperature of $50^{\circ} \mathrm{C}$ on thermogravimetric analysis (TGA). The pores generated in the cellulose acetate film were confirmed using a scanning electron microscope machine (SEM) and mercury porosimeter. Thermal stability and interactions in materials were measured using TGA and Fourier transform infrared (FT-IR).

\section{Introduction}

With rising awareness of various environmental problems such as water shortage and energy problems across the world, the interest in porous polymeric materials is also rising as a way to solve these problems. Porous polymeric materials are substances that have nano-sized pores, which are actively used in adsorbents, catalysts, water treatment and gas separation membranes, and electrical and chemical materials. (Li et al. 2019; Otaru et al. 2019; Xu et al. 2018; Notario et al. 2016; Rashidi et al. 2018; Samanta et al. 2019; Sun et al. 2016; Huang 2016) The separation process using porous polymer membranes is seeing a rapid growth in a variety of applications, despite its short history compared to other process technologies. This is because porous membranes have various advantages: easy to use, relatively low cost and space, environmental friendliness, and convenience of post-processing. (Costa et al. 2020; Fen Yong et al. 2020; George et al. 2016; Han et al. 2018; Karami et al. 2020; Luiso et al. 2020; Prasetya et al. 2020; Hussain et al. 2020; Cui et al. 2016; Sun et al. 2020)

Recently, many researchers have been devoted to solve the problems of separator permeability, selectivity, and chemical and thermal stability and the separator material to be environmentally friendly and inexpensive. Shasha Ma et al., studied a polypropylene (PP) composite membrane coated with PMMA and $\mathrm{AlPO}_{4}$ to improve the electrical and thermal stability of batteries. Since $\mathrm{AlPO}_{4}$ present in the coating layer was able to form a high electrolyte absorption and strong bond with PP, the membrane could have high ionic conductivity, which could lead to the thermal strengthening of the battery. (Ma et al. 2019) Dongwei Ma et al., studied a hydrophilicity of polysulfone modified by applying spray coating and selective swelling process technology. This made the membrane flexible and led to the control of porosity and pore size control. (Ma et al. 2020) Zhanghui Wang et al., prepared hydrophilic $\beta$-CD-PIM NPs and used them to effectively actuate interfacial bonding with polyamides. The additives showed excellent long-term durability, and also suggested the possibility of forming water transport nanochannels. (Wang et al. 2019) Ahmed Bhran et al., produced PVC/PVP membranes by effectively using phase-inversion technology. This showed a high salt removal rate, suggesting that it will be used effectively for future 
seawater treatment. (Bhran et al. 2018) Waqas et al., succeeded in manufacturing a membrane that was believed to be actively used for LIB of coin cells. PMDA and 4,4-oxydianiline were synthesized using electrospinning and thermo-compression. This membrane exhibited excellent porosity, electrolyte absorption, and ion conductivity. (Arifeen et al. 2020) Chaihong et al. reported that polybenzimidazole was synthesized and a polyethylene membrane was coated with a TPA crosslinking agent to make a CHBPBIE membrane for batteries. (Xue et al. 2020)

Recently, our research team has also conducted several studies to make separators more effective, in particular, the cellulose acetate (CA) separators. A new method for controlling the size and number of pores of the membrane and generating a pore path that is close to straightforward was proposed. The use of various additives and solvents was attempted in past studies. The process used in those studies were highly energy efficient, relatively low cost, and environment friendly. Forming several pores, controlling the pore size, and generating a pore path close to a straightforward can reduce the resistance in the cell separator and enable fast lithium-ion transport. Unfortunately, the formation of many pores in the CA separator with a relatively low molecular weight (MW 30,000 50,000) resulted in lowering the thermal stability of the membrane. This caused a fatal disadvantage, especially in the battery field. (Lee et al. 2016, 2018, 2019; Kim et al. 2019; Hong et al. 2020; Hwang et al. 2016) In this study, calcium oxide $(\mathrm{CaO})$ was used to develop a separator that maintains high porosity and solves the problem of low thermal stability. It was expected that the high melting point and particle size of $\mathrm{CaO}$ and its interaction with CA would enhance the thermal stability of the entire membrane.

\section{Experimental}

\subsection{Materials \& membrane preparation}

CA (MW 30,000), CaO (99.9\%), and Dimethylformamide (DMF, 99.8\%) were purchased from SigmaAldrich. Acetone was purchased from Daejung Chemicals. All experimental reagents were used as purchased without further processing. A 20wt\% CA solution dissolved in DMF and acetone (w/w 8:2) was stirred for 2 hours at RT. and then $0.006 \mathrm{~mol}$ of $\mathrm{CaO}$ compared to $1 \mathrm{~mol}$ of monomeric CA polymer was added and stirred for $48 \mathrm{~h}$. The prepared solution was cast on Teflon tape for a freestanding film by doctor blade. and then dried in a thermo-hygrostat $\left(25^{\circ} \mathrm{C}, 50 \%\right)$ for $23 \mathrm{~min}$. When $\mathrm{CaO}$ was added as an additive to the polymer matrix, the ratio of $\mathrm{CA}: \mathrm{CaO}$ was selected as 1:0.006 mol as a moderate ratio. Because a low ratio of $\mathrm{CaO}$ addition could generate a low porosity problem and a high ratio of the same could create a particle dispersion problem, the addition amount of $\mathrm{CaO}$ was selected as $0.006 \mathrm{~mol}$. As the drying time increased, the solvents rapidly evaporated, the chains became more rigid, and pores were not formed. Thus, 23 min was selected as the appropriate drying time.

\subsection{Characterization}

The dried $\mathrm{CA} / \mathrm{CaO}$ composite films were treated with a water treatment machine at 8 bar for 3 hours. The flux data was measured as $\mathrm{L} / \mathrm{m}^{2} \mathrm{~h}(\mathrm{LMH})$. A mercury porosimeter (AutoPore V9600 series, Micromeritics Inc.) and scanning electron microscopy (SEM, JEOL JSM 5600 LV) was used to monitor the 
characteristics of the pores and porosity of the $\mathrm{CA} / \mathrm{CaO}$ composite films. Samples were prepared by cutting the dried membrane for more than 24 hours after hydrostatic treatment. Fourier transform infrared (FT-IR, Varian FTS 3100) was utilized to confirm the interaction between the CA polymer matrix and $\mathrm{CaO}$. For IR measurement, the sample was dried for 3 days. and the overall portion of several films was measured to obtain average data. To find out the thermal stability of the polymer, thermogravimetric analysis (TGA, Mettler Toledo) was performed from $25^{\circ} \mathrm{C}$ to $800^{\circ} \mathrm{C}$ at a rate of $10^{\circ} \mathrm{C} / \mathrm{min}$.

\section{Results And Discussion \\ 3.1 Water flux data}

Table 1

The water flux data of $\mathrm{CA} / \mathrm{CaO}$ composite films at 0 bar and 8 bar

\begin{tabular}{|ll|}
\hline at $0 \mathrm{bar}\left(\mathrm{L} / \mathrm{m}^{2} \mathrm{~h}\right)$ & at $8 \mathrm{bar}\left(\mathrm{L} / \mathrm{m}^{2} \mathrm{~h}\right)$ \\
\hline 0 & 95.25 \\
\hline
\end{tabular}

Physical pressure was applied to $\mathrm{CA} / \mathrm{CaO}$ composite films through hydraulic pressure in order to observe the formation of pores. The pressure was maintained at 8 bar for more than 3 hours, and as seen from the water flux data, a water channels were formed. This flux measurement result showed an average of 95.25 LMH based on reproducible results more than 10 experiments.

\subsection{Porosimeter data}

Table 2

Porosimeter data of $\mathrm{CA} / \mathrm{CaO}$ composite films at $8 \mathrm{bar}$

\begin{tabular}{|ll|}
\hline Sample & CAVCaO composite films \\
\hline Porosity $(\%)$ & 73.1 \\
\hline Average pore diameter $(\mu \mathrm{m})$ & 1.62 \\
\hline
\end{tabular}

For a more detailed analysis, a mercury porosity meter was used. As a result of the measurement, data of a high porosity of $73.1 \%$ and an average pore diameter of $1.62 \mu \mathrm{m}$ were obtained. Considering the flux data and porosimeter data, it was confirmed that abundant pores were generated after $\mathrm{CaO}$ was added, more than the cellulose acetate polymer film in which nothing was added. The formation of pores in the $\mathrm{CA} / \mathrm{CaO}$ composite films rather than in $\mathrm{CA}$ without additives could be explained by the fact that some plasticized regions were formed in the existing chains due to the particle size of $\mathrm{CaO}$. Furthermore, some solvents were allowed to remain in the CA polymer chains by controlling the drying time. After hydrostatic treatment, the solvents were removed, resulting in the formation of water channels through the plasticized chain regions.

\subsection{SEM images of membrane}


The image of the CA polymer surface without additives dissolved in DMF and acetone (w/w 8:2) (Fig. 1(a)) showed that pores were not formed; however, pores were observed in the polymer to which $\mathrm{CaO}$ was added (Figure. 1(b)). Additionally, unlike previous studies, the newly discovered fact confirmed that pores of various sizes existed in one pore. (Figure. 1(c)). In the case of the cross section of the polymer matrix in which $\mathrm{CaO}$ (Figure. 1(d)) was used as an additive, the shape of the pores was sponge-like. Thus, it seemed that there were not many pores on the upper surface of the polymer film, but many pores were contained in one pore, and it was confirmed that these pores formed a sponge-type water channel. This could also explain the high values of the flux data and porosity data mentioned earlier

\subsection{FT-IR data}

Figure 2. FT-IR data of neat $\mathrm{CA}, \mathrm{CA} / \mathrm{CaO}$ composite at 0 bar, and $\mathrm{CA} / \mathrm{CaO}$ composite at 8 bar

Figure 3. Deconvolution data of ether group in (a) neat $\mathrm{CA}$, (b) $\mathrm{CA} / \mathrm{CaO}$ composite at 0 bar and (c) $\mathrm{CA} / \mathrm{CaO}$ composite at 8 bar

Table 3

Deconvoluted area of FT-IR data at ether group

\begin{tabular}{|llll|}
\hline \multirow{2}{*}{ Peak $\left(\mathrm{cm}^{-1}\right)$} & Area (\%) & \\
\cline { 2 - 4 } & Neat CA & CA/CaO at 0 bar & CA/CaO at 8 bar \\
\hline 981 & 8.66 & 8.45 & 8.04 \\
\hline 1031 & 80.76 & 81.61 & 83.11 \\
\hline 1075 & 10.58 & 9.94 & 8.85 \\
\hline
\end{tabular}

Figure 4. Deconvolution data of carbonyl group in (a) neat $\mathrm{CA}$, (b) $\mathrm{CA} / \mathrm{CaO}$ composite at 0 bar and (c) $\mathrm{CA} / \mathrm{CaO}$ composite at 8 bar

Table 4

Deconvoluted area of FT-IR data at carbonyl group

\begin{tabular}{|llll|}
\hline Peak $\left(\mathrm{cm}^{-1}\right)$ & Area (\%) & \\
\cline { 2 - 4 } & Neat CA & CA/CaO at 0 bar & CA/CaO at 8 bar \\
\hline 1731 & 72.77 & 76.54 & 79.46 \\
1753 & 27.23 & 23.46 & 20.54 \\
\hline
\end{tabular}

In Fig. 3, it showed that there was no change in the peak area in the ether group of CA, which indicated that $\mathrm{CaO}$ was not complexed to the ether group of $\mathrm{CA}$ when $\mathrm{CaO}$ was added. These changes were not observed even after hydraulic treatment. However, in Fig. 4, when $\mathrm{CaO}$ was added to the $\mathrm{CA}$, a shift of approximately $4 \%$ from the high wavenumber $(1753 \mathrm{~cm}-1)$ to the low wave number $(1731 \mathrm{~cm}-1)$ was observed. This suggested that the addition of $\mathrm{CaO}$ weakened the $\mathrm{C}-\mathrm{O}$ bond in the existing $\mathrm{CA}$ chain. The 
data after the hydraulic treatment at 8 bar showed that the shift to the low wavenumber was an additional $3 \%$. This indicated that when the water pressure treatment was carried out, $\mathrm{CaO}$ remained in the polymer chain. Additionally, as the mobility of the CA chain increased due to hydraulic pressure, more interactions with the surrounding $\mathrm{CaO}$ particles occurred. In most cases, when the particles penetrated the polymer chains, the distance between the CA chains increased, and as a result, the $\mathrm{C}-\mathrm{O}$ bond strengthened, consistent with the shift to higher wavenumbers in the IR spectrum. However, when the CaO particles were penetrated, the effect of weakening the $\mathrm{C}-\mathrm{O}$ bond caused by the interactions between the polymer chain and the surface of $\mathrm{CaO}$ particles became more pronounced than the previously mentioned effect, resulting in the shift to a lower wavenumber.

\subsection{TGA data}

Figure 5. TGA data graph of neat $\mathrm{CA}$ and $\mathrm{CA} / \mathrm{CaO}$ composite

The thermal stability of the $\mathrm{CA} / \mathrm{CaO}$ composite was measured using TGA. As shown in Fig. 5 , when the water pressure treatment was not applied, the CA without additives decomposed at approximately $260^{\circ} \mathrm{C}$. These phenomenon was attributable to the melting point of cellulose acetate (approximately $256^{\circ} \mathrm{C}$ ). However, the $\mathrm{CA} / \mathrm{CaO}$ composites decomposed at approximately $280^{\circ} \mathrm{C}$ and after water pressure treatment, the decomposition-starting temperature increased to $310^{\circ} \mathrm{C}$. In the aforementioned FTIR, the additional bonding of the $\mathrm{CA}$ chain with $\mathrm{CaO}$ was generated after hydraulic treatment. In addition, the high melting point of $\mathrm{CaO}$ at $2572^{\circ} \mathrm{C}$ would strengthen the thermal stability of $\mathrm{CA}$ polymer.

\section{Conclusion}

In previous studies, it was seen that porous cellulose acetates showed weak stability due to their low molecular weights, posing a hindrance to their practical applications. To compensate for these problems, this study proposed a method to improve the thermal stability of porous cellulose acetate films by changing the solvent, additives and drying time. In this study, water channels were formed in some flexible regions of the polymer chain by using a residual solvent controlled by drying time. In addition, $\mathrm{CaO}$ used as an additive with the high melting point was complexed with the carbonyl group in CA, generating the crosslinking effect. The average water flux data was $95.25 \mathrm{LMH}$ at 8 bar, and the porosity was $73.1 \%$. Through FT-IR, it was confirmed that $\mathrm{CaO}$ interacted with the carbonyl group of $\mathrm{CA}$, and more interactions were generated with carbonyl groups by increasing the mobility of polymer chains during hydraulic treatment. These results could be expressed in detail with Scheme1. Scheme 1(A) and (B) describe the interaction between the carbonyl groups of polymer and $\mathrm{CaO}$. Even after hydrostatic treatment, as shown in Scheme 1(C), the $\mathrm{CaO}$ particles remained and interacted with more carbonyl groups. The TGA data showed that the thermal strength of the $\mathrm{CA} / \mathrm{CaO}$ composite films improved. In detail, the decomposition temperature increased by approximately $50^{\circ} \mathrm{C}$ for the water-pressure-treated $\mathrm{Ca} / \mathrm{CaO}$ composite films compared to $\mathrm{CA}$ polymer without additives. These results show that the $\mathrm{CA} / \mathrm{CaO}$ composite showed not only high porosity but also enhanced thermal stability compared to neat CA films. 
It could be concluded that the method proposed in this study could solve the problem of low molecular weight CA separators and expand the use in various applications.

\section{Declarations}

\section{Acknowledgements}

This work was supported by a 2019 Sangmyung University research fund.

\section{References}

Arifeen WU, Kim M, Ting D, Kurniawan R, Choi J, Yoo K et al (2020) Hybrid thermal resistant electrospun polymer membrane as the separator of lithium ion batteries. Mater Chem Phys. 245:122780.

Bhran A, Shoaib A, Elsadeq D, El-gendi A, Abdallah H (2018) Preparation of PVC/PVP composite polymer membranes via phase inversion process for water treatment purposes. Chin J Chem Eng. 26(4):715-22.

Costa CM, Lizundia E, Lanceros-Méndez S (2020) Polymers for advanced lithium-ion batteries: State of the art and future needs on polymers for the different battery components. Prog Energy Combust Sci. 79:100846.

Cui X, Chen K, Xing H, Yang Q, Krishna R, Bao Z et al (2016) Pore chemistry and size control in hybrid porous materials for acetylene capture from ethylene. Science. 353(6295):141-4.

Fen Yong W, Zhang H (2020) Recent Advances in Polymer Blend Membranes for Gas Separation and Pervaporation. Prog Mater Sci. 10.1016/j.pmatsci.2020.100713

George G, Bhoria N, AlHallaq S, Abdala A, Mittal V (2016) Polymer membranes for acid gas removal from natural gas. Sep Purif Technol. 158:333-56.

Han Y, Ho WSW (2018) Recent advances in polymeric membranes for $\mathrm{CO}_{2}$ capture. Chin J Chem Eng. 26(11):2238-54.

Hong SH, Cho Y, Kang SW (2020) Highly porous and thermally stable cellulose acetate to utilize hydrated glycerin, Journal of Industrial and Engineering Chemistry. 91:79-84.

Huang X (2016) A facile approach to make high performance nano-fiber reinforced composite separator for lithium ion batteries. J Power Sources. 323:17-22.

Hussain A, Li D, Luo Y, Zhang H, Zhang H, Li X (2020) Porous membrane with improved dendrite resistance for high-performance lithium metal-based battery, J Membr Sci. 605:118108.

Hwang J, Choi J, Kim JM, Kang SW (2016) Water treatment by polysulfone membrane modified with tetrahydrofuran and water pressure. Macromol Res. 24(11):1020-3. 
Karami P, Khorshidi B, McGregor M, Peichel JT, Soa res JBP, adrzadeh MS (2020) Thermally stable thin film composite polymeric membranes for water treatment: A review. J Clean Prod. 250:19447.

Kim HY, Cho Y, Kang SW (2019) Porous cellulose acetate membranes prepared by water pressure-assisted process for water-treatment. J Ind Eng Chem. 78:421-4.

Lee WG, Hwang J, Kang SW, (2016) Control of nanoporous polymer matrix by an ionic liquid and water pressure for applications to water-treatment and separator. Chem Eng J. 284:37-40.

Lee WG, Kang SW (2018) Porous cellulose acetate by specific solvents with water pressure treatment for applications to separator and membranes. Macromol Res. 26(7):630-3.

Lee WG, Kang SW (2019) Control of pore in cellulose acetate containing Mg salt by water pressure treatment for applications to separators. J Ind Eng Chem. 70:103-6.

Li W, Xia F, Zhao S, Zhang M (2019) Characterization of liquid-liquid mass transfer performance in a novel pore-array intensified tube-in-tube microchannel. AIChE J. 66:6893

Luiso S, Fedkiw P (2020) Lithium-ion battery separators: Recent developments and state of art. Curr Opin Electrochem. 20:99-107.

Ma D, Wang Z, Liu T, Hu Y, Wang Y (2020) Spray coating of polysulfone/poly(ethylene glycol) block polymer on macroporous substrates followed by selective swelling for composite ultrafiltration membranes. Chin J Chem Eng. 10.1016/j.cjche.2020.05.002

Ma S, Lin H, Yang L, Tong Q, Pan F, Weng J et al (2019) High thermal stability and low impedance polypropylene separator coated with aluminum phosphate. Electrochimica Acta. 320:134528.

Notario B, Pinto J, Rodriguez-Perez MA (2016) Nanoporous polymeric materials: A new class of materials with enhanced properties. Prog Mater Sci. 78-79, 93-139.

Otaru AJ, Morvan HP, Kennedy AR (2019) Air flow measurement across negatively infiltration processed porous aluminum structures. AIChE J. 65:1355-1364

Prasetya N, Himma NF, Sutrisna PD, Wenten IG, Ladewig BP (2020) A review on emerging organiccontaining microporous material membranes for carbon capture and separation. Chem Eng $\mathrm{J}$. 391:123575.

Rashidi S, Esfahani JA, Karimi N (2018) Porous materials in building energy technologies-A review of the applications, modelling and experiments. Renew Sustain Energy Rev. 91:229-47.

Samanta P, Desai AV, Let S, Ghosh SK (2019) Advanced porous materials for sensing, capture and detoxification of organic pollutants toward water remediation. ACS Sustain Chem Eng. 7(8):7456-78. 
Sun H, Du Y, Gao C, Iftikhar, Long J, Li S, et al., (2020) Pressure-assisted in-depth hydrophilic tailoring of porous membranes achieving high water permeability, excellent fouling resistance and superior antimicrobial ability. Journal of Membrane Science. 604:118071.

Sun M, Huang S, Chen L, Li Y, Yang X, Yuan Z et al. (2016) Applications of hierarchically structured porous materials from energy storage and conversion, catalysis, photocatalysis, adsorption, separation, and sensing to biomedicine. Chemical Society Reviews. 45(12):3479-563.

Wang Z, Guo S, Zhang B, Zhu L (2019) Hydrophilic polymers of intrinsic microporosity as water transport nanochannels of highly permeable thin-film nanocomposite membranes used for antibiotic desalination. J Membr Sci. 592:117375.

Xue C, Jin D, Nan H, Wei H, Chen H, zhang C et al (2020) A novel polymer-modified separator for highperformance lithium-ion batteries. J Power Sources. 449:227548.

Xu Y, Lin L, Xiao M, Wang S, Smith AT, Sun.L et al (2018) Synthesis and properties of $\mathrm{CO}_{2}$-based plastics: Environmentally-friendly, energy-saving and biomedical polymeric materials. Prog Polym Sci. 80:163-82.

\section{Figures}

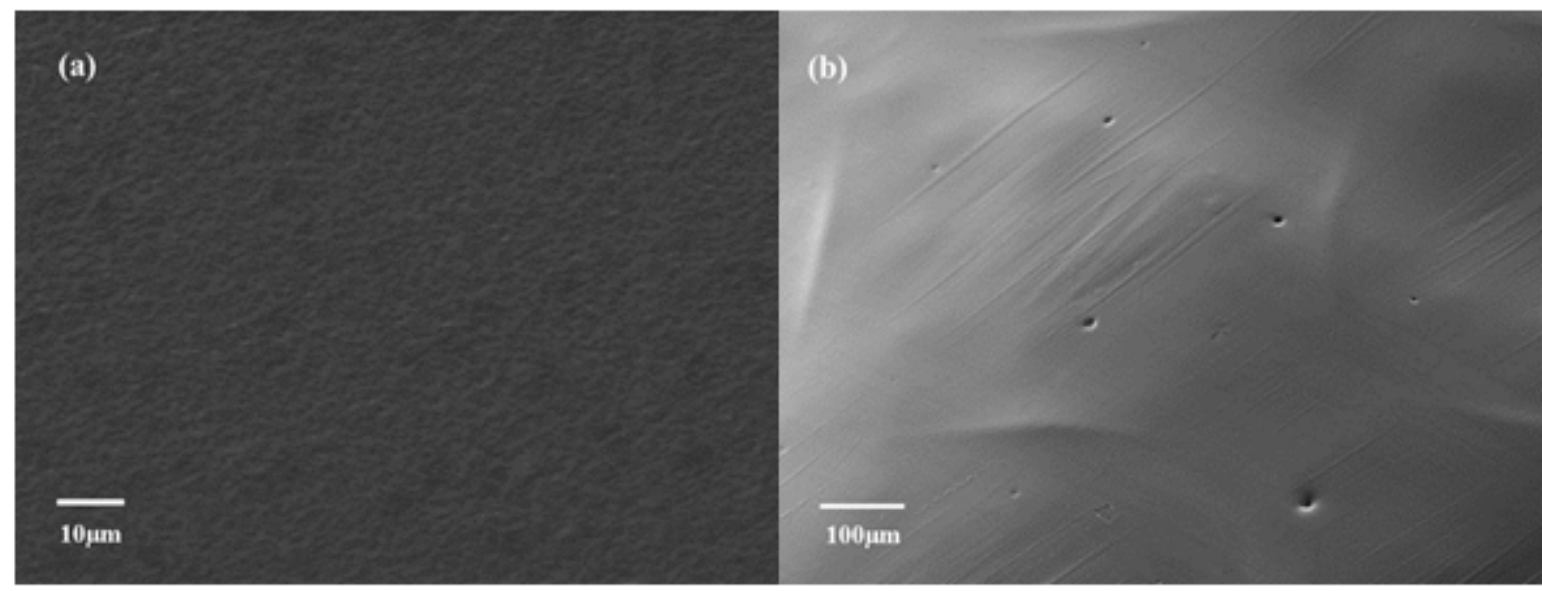

(c)

\section{(d)}


SEM image of (a) surface of neat $\mathrm{CA}$, (b) surface of $\mathrm{CA}$ added with $\mathrm{CaO},(\mathrm{C})$ enlarged view of one pores, and (d) cross section of $\mathrm{CA}$ with $\mathrm{CaO}$

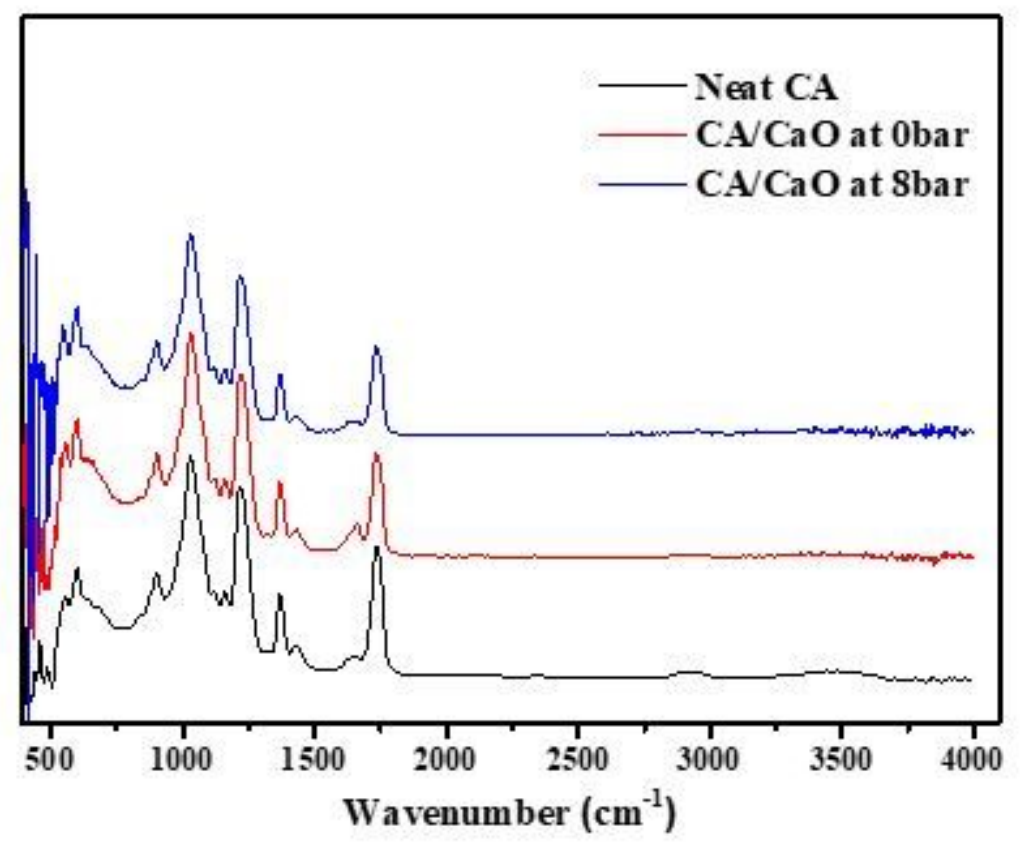

Figure 2

FT-IR data of neat $\mathrm{CA}, \mathrm{CA} / \mathrm{CaO}$ composite at 0 bar, and $\mathrm{CA} / \mathrm{CaO}$ composite at 8 bar

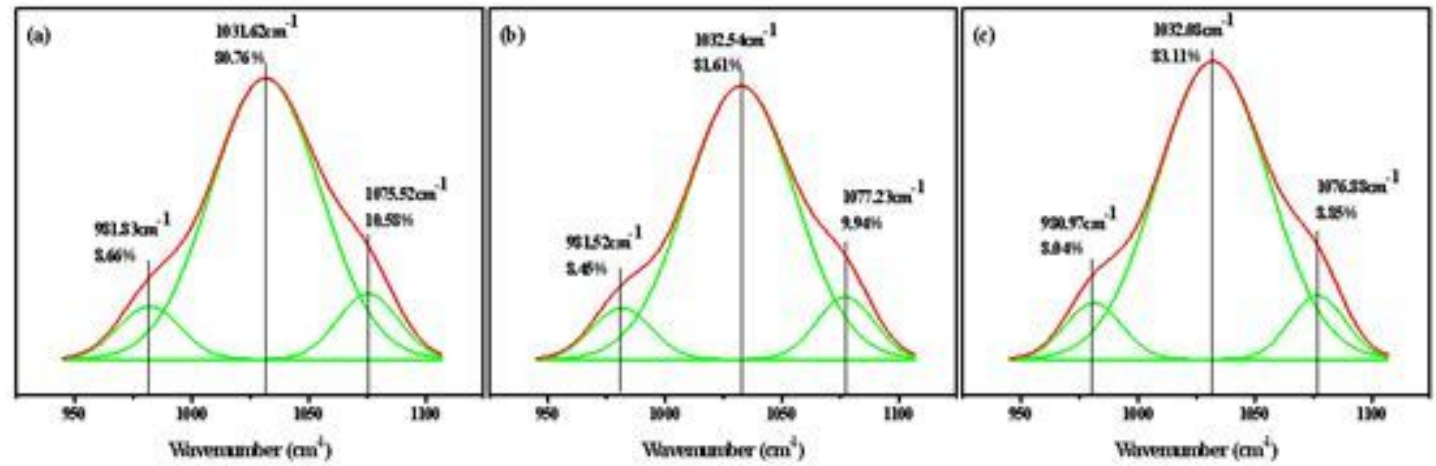

Figure 3

Deconvolution data of ether group in (a) neat $\mathrm{CA},(\mathrm{b}) \mathrm{CA} / \mathrm{CaO}$ composite at 0 bar and (c) $\mathrm{CA} / \mathrm{CaO}$ composite at 8 bar 

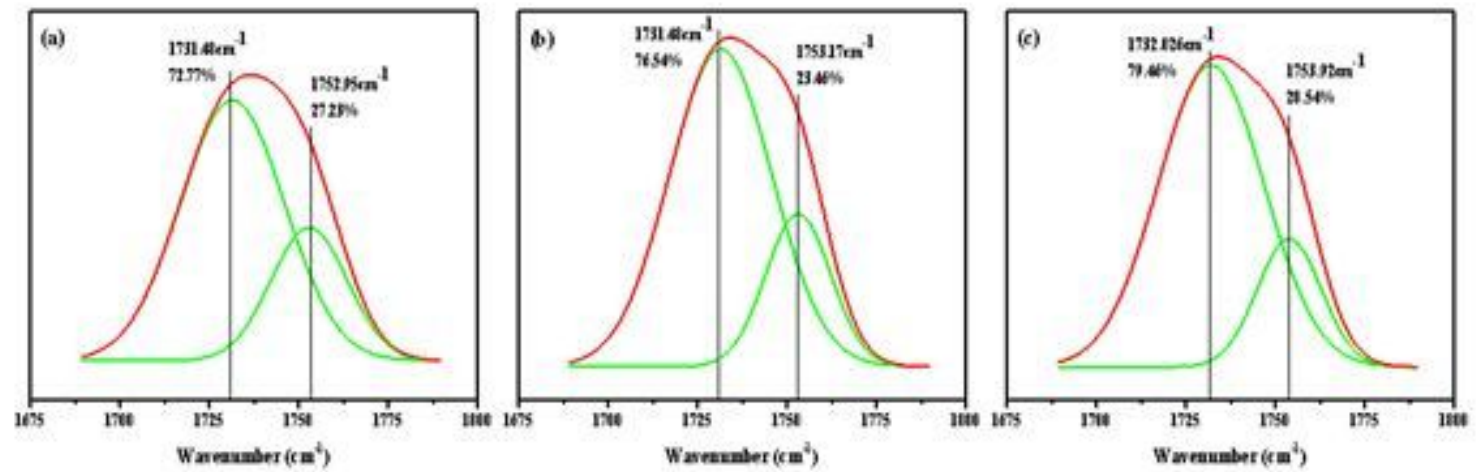

Figure 4

Deconvolution data of carbonyl group in (a) neat $\mathrm{CA}$, (b) $\mathrm{CA} / \mathrm{CaO}$ composite at 0 bar and (c) $\mathrm{CA} / \mathrm{CaO}$ composite at 8 bar

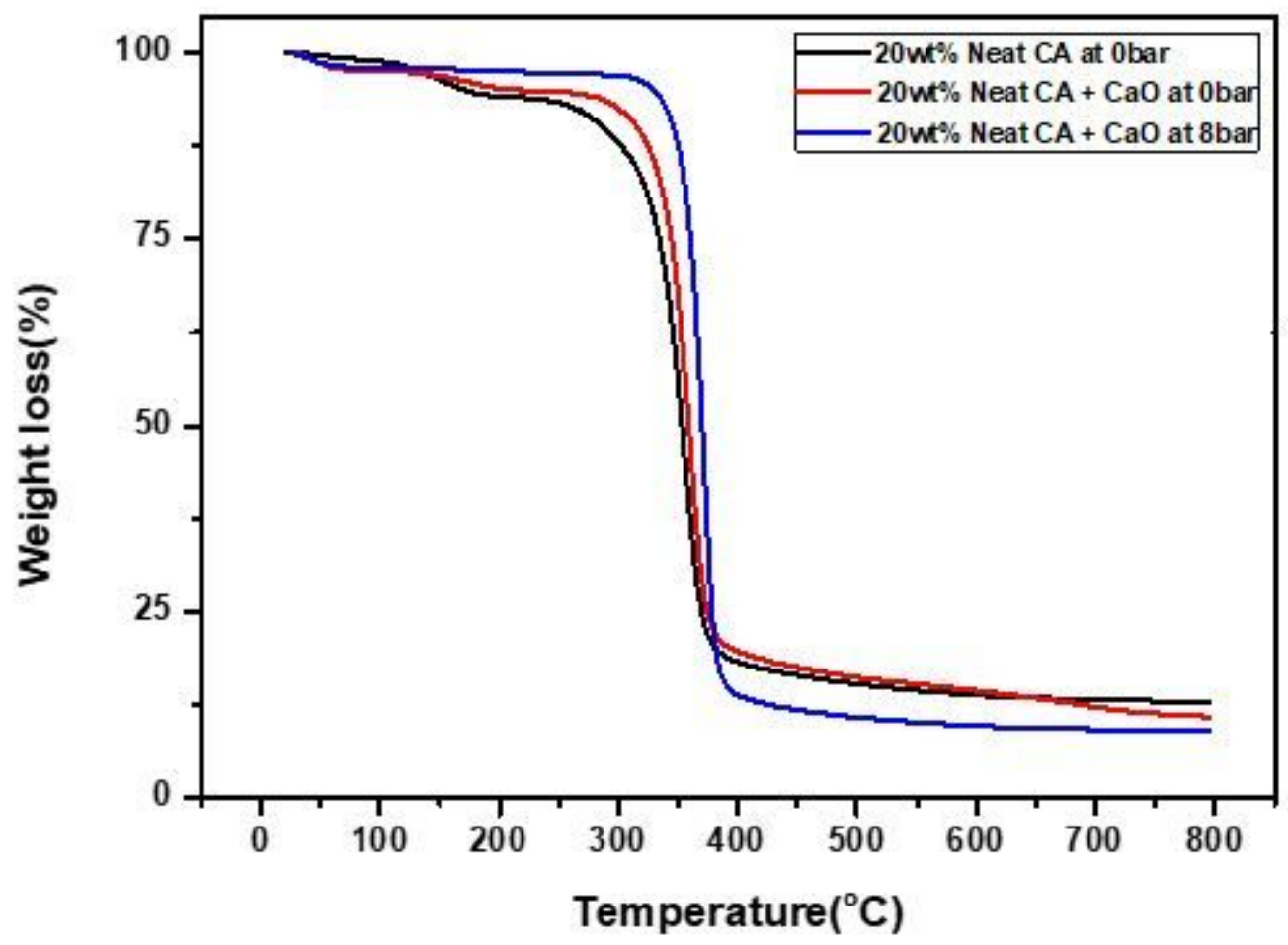

Figure 5

TGA data graph of neat $\mathrm{CA}$ and $\mathrm{CA} / \mathrm{CaO}$ composite

\section{Supplementary Files}

This is a list of supplementary files associated with this preprint. Click to download.

- scheme1.jpg 